\title{
A escrita atuante de Carl Einstein
}

Elena O'Neill"

\section{RESUMO}

Poeta de vanguarda que se tornou historiador e teórico da arte, mediador cultural entre França e Alemanha, Carl Einstein colaborou com diversas publicações (entre as quais Die weißen Blätter, Die Aktion, Das Kunstblatte Transition). Foi coeditor, com Georg Grosz, de Der blutige Ernst (1919) e, com Paul Westheim, de Europa-Almanach (1925), além de cofundador da revista Documents (1929) junto com Georges Bataille, Michel Leiris, Georges Wildenstein e Georges-Henri Rivière. Pertenceu ao círculo de Daniel-Henry Kahnweiler; conheceu Pablo Picasso, Georges Braque, Juan Gris e Fernand Léger. Este artigo se propóe a apresentar algumas das particularidades da escrita e do pensamento de Carl Einstein, sua coerência intelectual, assim como familiarizar o leitor com um âmbito intelectual excepcional, através da rede de diálogos, brechas e aberturas que seus escritos apresentam.

Palavras-chave: cubismo; linguagem; arte; teoria; liberdade.

\section{ABSTRACT}

Vanguard poet who later became a historian and art theorist, cultural mediator between France and Germany, Carl Einstein contributed to several publications, such as Die weißen Blätter, Die Aktion, Das Kunstblatt, and Transition. He was co-editor, together with Georg Grosz, of Der blutige Ernst (1919) and, with Paul Westheim, of Europa-Almanach (1925); along with Georges Bataille, Michel Leiris, Georges Wildenstein, and Georges-Henri Rivière, he was also co-founder of the magazine Documents (1929). He belonged to DanielHenry Kahnweiler's circle; he befriended Pablo Picasso, Georges Braque, Juan Gris, and Fernand Léger. This paper presents some of Carl Einstein's writings, the peculiarities of

\section{DOI - http://dx.doi.org/10.1590/2237-101X0173206}

Artigo recebido em 03 de novembro de 2015 e aprovado em 15 de março de 2016.

* Pontifícia Universidade Católica do Rio de Janeiro, Rio de Janeiro, RJ, Brasil.

Doutora pela PUC-Rio, Departamento de História Social da Cultura, na linha de História da Arte (2013) com a tese "Carl Einstein: por uma outra leitura da forma". Atualmente em Pós-doutorado no IART/UERJ (CAPES, PNPD). Este texto tem como origem algumas das questóes tratadas na comunicação apresentada no VI Congresso Internacional de Pesquisa (Auto)biográfica, intitulada "Carl Einstein entre textos e itinerários intelectuais”, na UERJ, Rio de Janeiro, em novembro de 2014, visando agora a uma reflexão mais ampla sobre algumas particularidades da escrita de Carl Einstein. Sua escrita não é fluida nem no original em alemão, nem quando escreve em francês; decidimos manter essa característica na nossa tradução dos textos aqui citados. 
his intellectual coherence and way of thinking, and aims at acquainting the reader with an exceptional intellectual milieu through the network of dialogues, gaps, and openings introduced by his writings.

Keywords: Cubism; language; art; theory; liberty.

Poeta, historiador e teórico da arte, editor e tradutor, representante e intérprete das vanguardas artísticas, literárias e políticas do começo do século XX, Carl Einstein ${ }^{1}$ (1885-1940) foi também um mediador cultural entre França e Alemanha, contribuindo à divulgação, reconhecimento e valorizaçáo da arte moderna. Contudo, Carl Einstein continua, em larga medida, um autor esquecido. ${ }^{2}$ Talvez pela complexidade e estranheza de sua escrita ou pelas múltiplas referências teóricas com as quais dialoga e debate; pela perda de textos e documentos decorrente de seus contínuos deslocamentos, devidos tanto à conjuntura europeia da época na qual atuou, assim como às consequências das duas Guerras Mundiais; ou ainda pelo simples fato de ele náo ter escrito no âmbito da Academia. Além disso, estudar Carl Einstein exige recuperar textos e autores quase abandonados na história da arte atual e revisar preconceitos arraigados.

\footnotetext{
${ }^{1}$ Carl Einstein nasceu em Neuwied, perto de Karlsruhe (Alemanha), em 1885. De família judia, estudou arte e filosofia na Universidade de Berlim, manteve uma relaçáo estreita com Franz Pfemfert, redator-chefe do Der Demokrat e criador da revista expressionista Die Aktion. Além da parceria na revista, havia laços familiares e de amizade: Pfemfert era casado com Alexandra Ramm e Einstein com sua irmá, Maria Ramm. De origem russa, Maria Ramm e suas irmãs participaram ativamente da vida cultural em Berlim, traduzindo vários autores russos publicados na Die Aktion, entre eles Trotski. Combatente na Primeira Guerra Mundial, foi transferido para a administração civil do governo-geral de Bruxelas em 1916; colaborou na repatriação de Adolphe Max, símbolo da resistência belga, e na organização da retirada ordenada dos soldados alemães em 1918. Em Berlim, juntou-se à Liga Spartakista e participou da revolução em dezembro de 1918. Foi um dos seis oradores no funeral de Rosa Luxemburg (1919) e engajou-se na Guerra Civil Espanhola (1936). Detido como resultado da aplicação das medidas do governo francês contra habitantes alemães na França, foi internado no campo para estrangeiros de Bassens, perto de Bordeaux, em 1940, e liberado junto com outros internos quando os alemães estavam próximos à área. Impossibilitado de escapar pela Espanha devido a sua participação na Guerra Civil (junto aos anarcossindicalistas na coluna Durruti), cometeu suicídio perto de Lestelle-Bétharram, França, em 1940. Foi enterrado em Boeil-Bézing (Pireneus).

2 Para Georges Didi-Huberman, o "esquecimento" de Carl Einstein decorre das dificuldades de tradução, do condicionamento do meio universitário a uma língua facilmente traduzível resultante do modelo anglo-saxão, da "falta" ou "olvido" de um modo de conhecimento com o qual a história da arte não sabe mais como lidar. Ver DIDI-HUBERMAN, Georges. O anacronismo fabrica a história: sobre a inatualidade de Carl Einstein. In: ZIELINSKY, Mónica (Org.). Fronteiras. Arte, crítica e outros ensaios. Porto Alegre: Ed. UFRGS, 2003, p. 19-55; DIDI-HUBERMAN, Georges. Tableau = coupure. Expérience visuelle, forme et symptôme selon Carl Einstein. Cahiers do Musée national d'art moderne, Paris, Centre Georges Pompidou, v. 58, p. 5-27, 1996.
} 
Entre suas obras teóricas mais importantes encontramos Negerplastik (1915). ${ }^{3}$ Apesar de ter sido publicada durante a Primeira Guerra Mundial, capturou a atenção tanto de especialistas como de amadores na Alemanha, se bem que na França eram poucos os que estavam familiarizados com as noçôes por ele discutidas. A publicação, breve, densa desde o ponto de vista teórico e inovadora pela abordagem de objetos até esse momento considerados como etnográficos nos museus da França, Bélgica e Alemanha, se destaca por tratar de uma arte que provocou e interessou a artistas como André Derain, Henri Matisse, Maurice de Vlaminck, Pablo Picasso e Georges Braque. Em grandes linhas, no plano teórico, Einstein discute as categorias de "pictórico" e "escultórico", e, independentemente do meio artístico empregado, ressalta as características da arte negra, as soluçóes espaciais na escultura encontradas pelos artistas africanos e sua similitude com as invençôes dos artistas cubistas na pintura. Os cubistas captaram que a figuração dos objetos mediante signos produziam diversos sentidos, assim como perceberam a combinação, transformação e reformulação de signos e de grupos de signos na escultura africana. Por outra parte, as esculturas da África nos mostram aquilo que os artistas sabem, não apenas o que eles olham. As esculturas são objetos reais inseridos no mundo, não precisam de uma base, um muro ou uma arquitetura preexistente; as máscaras, associadas a um suporte humano, funcionam como esculturas em movimento. Muros, bases e arquiteturas foram "apoios" frequentes na escultura europeia, definida por Carl Einstein como "baixo-relevo", que talvez tenha tido sua origem na proibição judaica de criar ídolos. Tais tendências iconoclastas atravessaram a arte cristã e fizeram da escultura um ornamento da arquitetura, com o qual se perdeu qualquer existência da escultura no espaço. Além dos múltiplos sentidos que a manipulação das esculturas negras admitia (por exemplo, a integração a outros conjuntos), as dimensões, a monocromia, assim como seu caráter de signo, distinguia essas esculturas dos seres vivos com os quais compartiam o espaço. ${ }^{4}$

Com um olhar livre de preconceitos ou eurocentrismos, Carl Einstein confere à escultura negra o estatuto de arte de primeiro nível. Aproximando as invençóes cubistas à escultura negra, analisando a arte africana a partir de categorias não africanas, o autor aspira a uma

\footnotetext{
${ }^{3}$ EINSTEIN, Carl. Negerplastik. Leipzig: Verlag der Weißen Bücher, 1915. Reedição. Munique: Kurt Wolff Verlag, 1920. Um ano depois, uma versão em francês, EINSTEIN, Carl. L'art nègre. Remarques sur la méthode (cap. 1). Action. Cahiers de philosophie et d'art. Paris, v. 2, n. 9, p. 12-16, out. 1921. (Sem nome do tradutor); em 2008, uma primeira versão em português foi publicada na revista Concinnitas, Rio de Janeiro, Uerj, v. 1, n. 12, p. 165-177, jul. 2008, com tradução de Inês de Araújo; em 2011, pela editora da UFSC e sob a direçáo de Liliane Meffre, o texto traduzido por Inês de Araújo, com as 119 imagens da edição original (1915) (EINSTEIN, Carl. Negerplastik (1915). Florianópolis: Editora UFSC, 2011. Publicado sob a direção de Liliane Meffre. Legendas estabelecidas por Ezio Bassani e Jean-Louis Paudrat. Tradução de Inês de Araújo. Apresentação de Liliane Meffre. Anexo de Roberto Conduru).

${ }^{4} \mathrm{O}$ exame minucioso da pintura e escultura que Einstein inaugura tanto em Negerplastik (1915) quanto em $A$ arte do século XX (1931) tem como interlocutores, entre outros, Adolf Hildebrand, Konrad Fiedler, Alois Riegl e Heinrich Wölfflin. A extensão deste artigo e seu recorte temático limitam a possibilidade de desenvolver com mais profundidade esta questão. Por mais informação sobre este tema, ver O’NEILL, Elena. Carl Einstein: por uma outra leitura da forma. Rio de Janeiro: PUC-Rio, 2013. (Tese de doutorado).
} 
reestrutura da visão sem referência a um repertório prévio de imagens, próprias de uma obra ou gênero de arte, de um artista ou de um período artístico. Critica o conceito de "primitivismo", no sentido utilizado à época - estado arcaico de um desenvolvimento artístico ou cultural progressivo. Para ele, a noção de primitivismo ultrapassa o preconceito eurocêntrico do termo, destacando o aspecto plástico dos objetos, resultado de uma experiência dinâmica não mediada por convençôes e preconceitos. Trata-se do processo visual enquanto experiência original e constitutiva do real: a imagem resultante desse processo não é, para ele, apenas um resíduo inerte da sensação ou da percepçáo.

Apesar de algumas questôes etnográficas do livro poderem ser questionadas, o que interessa é o descobrimento europeu da arte negra desde o ponto de vista plástico e a formulação teórica de uma visão plástica do espaço. Uma primeira tentativa de assimilar o pensamento teórico de Einstein em Negerplastik aponta para uma abordagem enraizada na Kunstwissenschaft germânica: entre outros, na autonomia da obra de arte defendida por Konrad Fiedler, na Kunstwollen de Alois Riegl, no pensamento teórico sobre o espaço no fim do século XIX e começos do século XX. Mas Negerplastik também ecoa o pensamento de Georg Simmel. ${ }^{5}$ Apenas para citar alguns pontos dessa ressonância: a compreensão de cultura artística — não como uma somatória de obras particulares e sim como aquilo que modela os valores da vida segundo normas de valor estético - ; a capacidade de compreender a união entre o sensível e o inteligível e a vida como confluência de pensamento e sensibilidade; um entendimento da arte, da filosofia e da religiáo para além da divisão tripartite estabelecida por Hegel. ${ }^{6}$ Incluir Simmel no horizonte abre ante nós a possibilidade de uma leitura da obra de Einstein em sintonia com o devir do mundo e o desenvolvimento, desdobramento e novas formulaçóes no campo das artes. Desse modo, dialogando com a obra de Einstein e nela encontrado o pensador, evitaríamos reduzir seu pensamento - e sua obra — a uma soma de mudanças e

\footnotetext{
${ }^{5}$ Georg Simmel (1858-1918), sociólogo, filósofo e crítico alemão, professor da Universidade de Berlim entre 1885 e 1914. Carl Einstein estudou na Universidade de Berlim em 1905, 1906 e 1908. Foi aluno de Georg Simmel (sociólogo), Alois Riehl (trata-se do filósofo, não de Alois Riehl, historiador da arte e curador do departamento têxtil do Museu de Artes Aplicadas, em Viena), Otto Hintze (historiador), Heinrich Wölfflin (historiador da arte), Ulrich von Wilamowitz (filólogo) e Kurt Breysig (historiador), professores universitários que se destacaram pela originalidade de pensamento e pelo não conformismo. Riehl ministrava cursos sobre Schopenhauer, Nietzsche e Kant; Simmel, cursos de Filosofia Geral e de Psicologia Social, assim como um curso particular sobre Estética; além dos cursos na Universidade, Wölfflin organizava trabalhos práticos nas coleçôes dos museus de Dahlem; Breysig apresentava suas ideias sobre a evolução da cultura com uma abordagem sociológica e antropológica, incitando seus alunos a se interessarem pela literatura medieval.

Einstein frequentou o curso de Simmel intitulado "Ética e princípios da concepção filosófica do mundo" no semestre de 1905-1906, e muito provavelmente também outros cursos ministrados pelo filósofo-sociólogo (MEFFRE, Liliane. Carl Einstein (1885-1940). Itinéraires d'une pensée moderne. Paris: Presses de l'Université Paris-Sorbonne, 2002, p. 32-35).

${ }^{6}$ Ultrapassa os limites deste artigo entrar na influência do pensamento de Hegel na História da arte. Por uma visão da complexidade da questáo, ver GOMBRICH, Ernst. Hegel e a história da arte. Gávea, Rio de Janeiro, PUC-Rio, n. 5, p. 57-72, 1988; GOMBRICH, Ernst. In Search of Cultural History. Londres: Oxford University Press, 1969.
} 
causas dessas mudanças; uma abordagem que permite vislumbrar um pensamento original e que ultrapassa os limites frequentemente atribuídos à teoria e história da arte.

A escrita de Einstein não se encaixa nem se estrutura numa análise do contexto histórico social. Ao contrário, ela diz respeito à existência enquanto esforço por ultrapassar os limites da linguagem, que ele considerava como limites do mundo. Einstein adjudicou à arte e à linguagem a tarefa de libertar o homem de imagens ossificadas e modos de pensar rígidos. ${ }^{7}$ Em Einstein, a realidade se constrói e se transforma sem cessar: ele defende uma arte na qual o artista modifica a realidade e não está preso a um excesso de racionalização, normatização ou a uma linguagem aprendida; acredita numa arte engajada na transformação social, na qual a forma reconfigura a subjetividade. ${ }^{8}$ Ao reformular os limites do mundo na procura de novas fronteiras do real, as novas formas artísticas redimensionam o real e o transformam na soma de todos os processos vitais. Apenas como amostra: aos novos meios descobertos pelos pintores cubistas para libertar o espaço das travas da perspectiva que a ciência impusera à arte desde o Renascimento, Einstein respondeu reformulando as categorias de análise crítica para dar conta dessas invençôes artísticas. Uma operação que vai além da dualidade entre forma e conteúdo ao incluir ativamente as duas partes sem fixar uma delas para poder enxergar o desenvolvimento da outra. Considerando que a discussáo sobre forma era táo densa e intensa no começo do século XX, é de se perguntar por que hoje em dia a questão da forma ativa vem sendo inviabilizada por leituras estéreis que reduzem a forma à morfologia e à composição??

\footnotetext{
${ }^{7} \mathrm{Na}$ carta datada junho 1923, Einstein apresenta seu projeto a Daniel-Henry Kahnweiler. Numa passagem menciona a influência do cubismo no modo de considerar objetos e sensaçóes e se questiona em relação à linguagem literária. "Veja bem, em Bebuquin as coisas habituais se tornam ridículas e grotescas frente às experiências verdadeiramente fundamentais. Do mesmo modo em que, sob a visada da experiência cubista, a imagem habitual se tornou em certa medida insuficiente, talvez inclusive falsa." "Voyez-vous, dans Bebuquin les choses habituelles deviennent ridicules et grotesques face à des expériences vraiment fondamentales. Exactement comme l'image habituelle est devenue, en regard de l'expérience cubiste, en un certain sens insuffisante, peut-être même fausse. Je suis donc d'avis qu'il faut aller plus loin dans ce sens." EINSTEIN, Carl; KAHNWEILER, Daniel-Henry. Correspondance 1921-1939. Marselha: André Dimanche Editeur, 1993, p. 54. Tradução nossa).

${ }^{8}$ Em alemão, os termos Form (substantivo) e formen (verbo) compartem a mesma raiz, o que ajudaria a entender a noção de forma em Einstein e a potência que ele adjudicou à mesma. Uma passagem de Bebuquin deixa entrever a complexidade com a qual o autor tratava o termo: "Talvez da forma nascem novos objetos; ela está mais afastada de suas origens que o conceito e minhas deduçôes dela são completamente diferentes das conceituais. Nela, a visão ganha uma força que anteriormente só era atribuída ao conceito" ("Vielleicht gebiert die Form neue Gegenstände; sie ist von ihrem Ursprünglichen entfernter, als der Begriff, und meine Deduktion von ihr ist durchaus von einer begrifflichen unterschieden. Die Anschauung gewinnt in ihr eine Kraft, die vorher dem Begriff allein zugesprochen wurde"). EINSTEIN, Carl. Bebuquin oder die Dilettanten des Wunders [1912]. In: EINSTEIN, Carl. Werke. Band I. Berlim: Medusa Verlag, p. 84. Tradução nossa)

${ }^{9}$ Desde o início do século XX até os dias de hoje a forma, conceito central na história da arte moderna, foi debatida por seus partidários e detratores, por críticos, historiadores e teóricos da arte, arquitetos e psicólogos da Gestalt. A arte segundo Konrad Fiedler não é uma forma que se deduz da realidade, mas sim uma forma que se imprime a esta. Wölfflin utiliza a técnica de comparação de imagens lado a lado para mostrar diferenças e polaridades na arte, focalizando na linha, cor e forma, reflexo da circunstância histórica e o contexto
} 
Dialogar com sua obra demanda uma leitura ativa que, junto à função por ele atribuída à linguagem literária e artística, nos leva a pensar na convivência e coexistência de processos criativos com formas de violência e destruição, na possibilidade de recuperar contradiçôes e incongruências da vida, dos sonhos e dos pesadelos; qualidades que, a meu ver, são possíveis só desde uma liberdade total. Por exemplo, sua autobiografia, conscientemente parcial, escrita depois de 1928 e publicada em 1930, na qual ele narra a sua experiência em uma sociedade estratificada e hierarquizada; a falta de charme de sua cidade natal; as lembranças dos prédios lúgubres da escola que, no passado, eram a prisão do castelo; a sensação duradoura da ignorância de professores que não acreditavam na lei de gravidade em virtude de sua religiosidade. Curiosamente, o texto finaliza com a sua ida para Berlim (1905), a entrada na universidade na época na qual escrevia seu romance Bebuquin:10 "Blei o imprimiu nos Opale e, desse modo, com vinte anos entrei na literatura." ${ }^{11}$

Redigido entre 1906 e 1908, dedicado a André Gide, Bebuquin é um texto de menos de cinquenta páginas. Peça literária crucial da literatura alemã e fonte de inspiração para dadaístas, Daniel-Henry Kahnweiler qualifica o livro como romance cubista e a Einstein

social da obra. Estabelecendo os pares linear e pictórico, superfície e profundidade, forma aberta e forma fechada, multiplicidade e unidade, clareza e náo clareza, ele determina diretrizes para analisar a passagem do Renascimento para o Barroco, demonstrando como o espírito de uma época nova exige uma forma nova. Para Einstein, as novas formas artísticas reformulam limites e visóes do mundo, estabelecendo e demarcando novas fronteiras do real (ver nota 9).

$\mathrm{Na}$ arquitetura são conhecidos os ditados de Louis Sullivan, "a forma segue à função", e o de Frank Lloyd Wright, "a forma é a função", não se referem à configuração material da forma nem reduzem a forma a um espaço delimitado: dizem respeito à forma como configuração entre arquitetura e sujeito. $\mathrm{Na}$ Bauhaus de Walter Gropius, a unidade entre método didático e processo produtivo, assim como um ensino prático que apontava a habituar aos jovens a uma percepção exata e imediata dos fatos formais, tendia a desenvolver e reforçar sensação e percepção como momentos ativos da consciência, não meras premissas da forma, mas a própria forma. Gropius não visava à criação, mas a criatividade como atividade da consciência.

Entre os críticos, historiadores e teóricos da arte que escreveram sobre a noção, encontramos PANOFSKY, Erwin. La perspectiva como forma simbólica (1924). Barcelona: Tusquets Editores, 1999; PEDROSA, Mário. Forma e percepção estética. São Paulo: Edusp, 1995. Para alguns posicionamentos mais recentes no debate sobre forma e formalismo, ver BOIS, Yve-Alain. Ideologia da forma. Novos estudos CEBRAP [online], n. 76, p. 237249. Disponível em :<http://www.scielo.br/scielo.php?script=sci_arttext\&pid=S0101-33002006000300013>; NAVES, Rodrigo. Entrevista com Rodrigo Naves (realizada em dezembro 2005). Número, n. 7. Disponível em: <http://www.forumpermanente.org/rede/numero/rev-numero7/entrevRodrigoNav>.

${ }^{10}$ Publicado parcialmente na revista de Franz Blei (Die Opale 2. Blätter für Kunst \& Literature.Leipzig: J. Zeitler, 1907, p. 169-175), sob o título Herr Giorgio Bebuquin. Em 1912, Die Aktion o publica em formato de série, sob o título Bebuquin oder die Dilettanten des Wunders. A versão definitiva, com o mesmo título e em formato de livro, foi publicada em dezembro de 1912, com prefácio de Franz Blei, e em 1917 na coleção organizada por Franz Pfemfert, sob o título Bebuquin. EINSTEIN, Carl. Bebuquinoder die Dilettanten des Wunders. Berlim/Wilmersdorf: Verlag Die Aktion, 1912; EINSTEIN, Carl. Bebuquin. Berlim/Wilmersdorf: Verlag der Wochenschrift Die Aktion, 1917 (Aktionsbücher der Aeternisten, Band 5).

11 "Damals schrieb ich Bebuquin: Blei druckte das in den Opalen und damit war man zwanzig und in der Literatur.” EINSTEIN, Carl. Kleine Autobiographie. In: Werke, Band 3. Berlim/Viena: Medusa Verlag, 1985, p. 111. Tradução nossa. 
como "poeta alemão cubista", ${ }^{12}$ distinguindo-o assim dos expressionistas. Publicado pela editora Die Aktion em 1912 e como Aktionsbücher der Aeternisten em 1917, o editor Franz Blei expressou seu desejo de que o livro permanecesse trinta anos nas prateleiras da editora, porque esse seria o tempo necessário "para ocupar-se dos livros que formaram a literatura de nossa época". ${ }^{13}$

Contrariando a literatura de formação da Bildung, o livro não se baseia no desenvolvimento intelectual ou espiritual do personagem principal; também náo admite narrador, intriga ou história. O protagonista/anti-herói é uma hipótese implausível de ser comprovada: Bebuquin não é um personagem de carne e osso. O "romance" consta de vários episódios, complementares e díspares, sem origem nem fim precisos, atravessados por reflexôes sobre a morte, a ideia platônica, Deus e outros conceitos. Personagens grotescos, extravagantes e absurdos agem em um espaço imaterial, sem perspectiva, em constante metamorfose. Relato que combina o real e o fantástico e apaga as fronteiras entre ambos, contra a representação e a descrição realista que caracterizam o século XIX, Bebuquin exige a participação ativa do leitor. A presença do autor, sugerida pelo emprego constante de espelhos e reflexos que veiculam funçóes e disfunçôes do psiquismo vivenciadas pelo protagonista, atua como uma sombra que se gruda ao leitor. As imagens fraturadas ou deformadas pela ação da luz remetem à problemática cubista: ultrapassam a realidade imediata e alcançam realidade plástica própria. Contrário a uma cultura da subjetividade, da metáfora e da interioridade, o romance desafia as leis da escrita na busca de renovação do signo. Carl Einstein participa do acontecimento vivenciado pelo protagonista com sua preocupação de encontrar um modo de escrever sobre sensaçóes e experiências vividas, sem reduzi-las a uma descrição convencional. Inquietação que, junto com a questão — concreta e teórica — da possibilidade de criação artística absoluta e o empenho em teorizar uma experiência visual imediata, atravessa seus escritos sobre arte.

O nome do personagem principal, Bebuquin, aparece no título do livro e leva a pensar a respeito do hábito de catalogar um livro que inclui o nome de uma figura relevante como monografia ou biografia. Contudo, a inclusão de um nome próprio no título surge também na sua última obra publicada em vida, Georges Braque, de 1934. Contrariamente ao que suporíamos, o livro não é uma monografia sobre o pintor; é um estudo do cubismo e suas transformaçôes no contexto histórico e cultural de 1930. Logo no início, Einstein explici-

\footnotetext{
12 "Je me souviens que Carl Einstein — dont je dirai sous peu le rôle de 'poète cubiste allemand' — dans des entretiens avec moi, reprochait précisément aux poètes cubistes français de n’avoir ni inventé des mots nouveaux, ni rejeté la syntaxe française." KAHNWEILER, Daniel-Henry. Juan Gris. Sa vie, son oeuvre, ses écrits. Paris: Gallimard, 1946, p. 180. Tradução nossa.

13 "Je ne puis souhaiter à ce livre, à votre livre, que de rester invendu chez son éditeur, afin que le lecteur espére l'y trouve d'ici trente ans, car c'est, je crois, le temps qu'il faudra pour qu'on s'occupe alors des quelques livres qui ont formé la litterature de nos jours." Carta de Franz Blei a Carl Einstein, que acompanhou as publicaçôes de Bebuquin em 1912 e 1917. In: EINSTEIN, Carl. Bébuquin ou les dilettantes du miracle (1912). Paris: EST-Samuel Taste Éditeur, 1987, p. 10. Tradução nossa.
} 
ta sua compreensão da história da arte e a necessidade de ultrapassar "uma normatização democrática aburguesada que serve a uma historiografia segundo a qual se falsifica e se deforma o devir numa perspectiva idealista". ${ }^{14}$ A crítica à monografia, que para Einstein "frequentemente afirma a apoteose do eu pequeno-burguês na qual o burguês se enxerga com um deleite voluptuoso [...] a monografia é o perigo de separar categoricamente o homem de sua obra e de arrancá-los das relaçóes significativas", ${ }^{15}$ se corresponde com uma concepção de homem que inclui também tudo o que ele produz.

Mas, precisamente, um artigo de Einstein publicado na revista transition, de Eugène Jolas, com motivo do centenário da morte de Goethe e intitulado "Obituary 1832-1932", desenvolve esta questão e levanta outros pontos relevantes. O texto, uma crítica violenta ao poeta, considerado o protótipo da Bildung e contra a qual Einstein arremete ao longo de sua obra, exige entender o que significa Goethe na tradição alemã e torna necessária a distinção entre Bildung como processo e Bildung como resultado. Muitas vezes identificada com a noção de cultura, a Bildung não é um problema menor, já que diz respeito à influência de uma tradição intelectual sobre a sociedade, atingindo a literatura e a estética. ${ }^{16}$ Autor representativo da literatura alemá, o exemplo de Goethe como poeta é de humildade e persistência na procura do objeto supremo, do núcleo vital do mundo, da força natural pulsante que toma as formas mais diversas, do qual apenas se faz alusão e impossível de capturar ou conquistar. Muito sucintamente, e no contexto alemão de 1914, o ideal da Bildung defende, por um lado, a sobrevivência da comunidade com uma tendência a obediência e submissão às autoridades políticas e sociais e, por outro, um desenvolvimento interior zelosamente cultivado. $\mathrm{O}$ alemão vive em uma comunidade com a qual se identifica, uma comunidade antes de tudo cultural: é homem enquanto é alemão. O intelectual alemão se desvia da sociedade civil, formada por indivíduos, ao mesmo tempo que, no seu interior, pensa como indivíduo e se dedica a cultivar-se e desenvolver-se. ${ }^{17}$ Porém, foi Georg Simmel quem percebeu a dupla significação do termo "individualismo" ao distinguir entre individualismo formal (da

14 "C'est à une telle normalisation bourgeoisement démocratique que servait une historiographie en vertu de laquelle se falsifiait et se déformait le devenir de l'art dans une perspective idéaliste." EINSTEIN, Carl. Georges Braque (1934). Bruxelas: Éditions La Part de l'Oeil, 2003, p. 14. Tradução nossa.

15 "Nous sommes cependant contraints de rompre avec la vision rapprochée de la monographie; celle-ci proclame d'habitude l'apothéose du moi petit-bourgeois en qui le bourgeois se mire avec une délectation voluptueuse [...] La monographie, c'est le danger de séparer trop nettement l'homme et son oeuvre et de les arracher aux rapports significatifs." EINSTEIN, Carl. Georges Braque (1934). Bruxelas: Éditions La Part de l'Oeil, 2003, p. 16. Tradução nossa.

${ }^{16}$ Louis Dumont trata da noçáo de Bildung e analisa comparativamente a ideologia francesa e a ideologia alemã, em DUMONT, Louis. L'idéologie allemande. France-Allemagne et retour. Paris: Gallimard,1991.

${ }_{17}$ Os termos Bild (imagem), bilden (representar, formar), gebildet (culto, instruído, educado), gebildete (elite intelectual), Vorbild (modelo), Ausbildung (formação por desenvolvimento), Anbildung (formação por adaptação), Bildsamkeit (flexibilidade ou plasticidade), Nachbild (cópia, reprodução) e Urbild (arquétipo), expressóes que pertencem à mesma família, sugerem a complexidade do ideal da Bildung. 
semelhança) e individualismo qualitativo (da singularidade). ${ }^{18}$ Foi ele quem compreendeu o desvio de Goethe em Os anos de aprendizado de Wilhelm Meister (1796), considerado exemplo de romance da Bildung, de transformar a passagem da formação de si em uma recomendação de abertura à comunidade, que no final do romance é considerada pelo poeta como a verdadeira conquista de Wilhelm Meister. ${ }^{19}$ Questôes que se entrelaçam com a arremetida por parte de Einstein contra a Bildung e o eu hipertrofiado, contra o eu como retrospectiva, tanto quanto com a luta pela liberdade, e sua preocupação com a linguagem.

No ensaio de Einstein citado anteriormente, publicado na revista transition em 1932, que segundo Jolas arrasa com a lenda de Goethe no momento em que as editoras publicaram uma avalanche de coletâneas em comemoração do centenário da sua morte, duas passagens deixam entrever o seu posicionamento:

É realmente repulsivo ver, também, como Goethe considera cada momento de sua vida como importante, e, temendo à morte, prepara seu monumento biográfico.

Muito elogio tem sido dado ao sereno olho olímpico deste virtuoso do indireto e da metáfora, do qual o humanista deduz sua vaidade e megalomania. [...]

A este homem, possuído de uma mania egocêntrica (noutras palavras, a este homem não extático), o "eu", essa personalidade que ele tentou conservar em autobiografias, é um assunto muito importante. Possuído por ele mesmo, ignora o fato de que o "eu" fica submerso no ato e é esquecido, e de que só podemos atuar na medida em que o "eu" é destruído. Porque o "eu" não é mais do que um suplemento de uma perspectiva em retrospectiva; cada ato é extático e só pode acontecer por meio da destruição do "eu". ${ }^{20}$

\footnotetext{
${ }^{18}$ Segundo o sociólogo, "a individualidade sempre significa por um lado, uma relação com o mundo, grande ou pequena, relação que pode ser tanto de açôes ou ideias, de recusa ou de assimilação, de dominação ou de servidão, de indiferença ou de intenso interesse; mas, por outro lado, significa que se trata de um mundo em ele mesmo, centrado sobre si mesmo, de certo modo autossuficiente e fechado sobre si mesmo. [...] Nós chamamos individualidade a maneira em que este duplo significado da existência humana tem a capacidade ou o desejo de juntar-se na unidade. Isto pode ocorrer numa grande variedade de graus e ênfases". ("L'individualité signifie toujours d'un côté un rapport au monde, grand ou petit, rapport qui peut être d'actions ou d'idées, de rejet ou d'assimilation, de domination ou de servitude, d'indifférence ou d'intérêt passionné; mais de l'autre côté elle signifie que cet être est un monde pour lui même, centré sur lui même, d'une certain façon autosuffisant et fermé sur lui même. [...] Nous appelons individualité la façon sous laquelle cette double signification de l'existence humaine a la capacité ou le désir de se rassembler dans l'unité. Cela peut se produire en une grande diversité de degrés et d'accentuations." In: SIMMEL, Georg. Philosophie de la modernité: la femme, la ville, l'individualisme(1917). Paris: Payot, 1989, p. 282-283. Traduçâo nossa).
}

A questão do individualismo foi largamente tratada em SIMMEL, Georg. Individualismo. In: SIMMEL, Georg. Goethe (1913). Buenos Aires: Prometeo Libros, 2005, pp. 129-151; SIMMEL, Georg. L'individualisme; l'individu et la liberté. In: SIMMEL, Georg. Philosophie de la modernite: la femme, la ville, l'individualisme(1917). Paris: Payot, 1989, p. 281-304.

${ }^{19}$ SIMMEL, Georg. Individualismo. In: SIMMEL, Georg. Goethe (1913), op. cit., p. 129-152; DUMONT, Louis. La Bildung representée: Les années d'apprentissage de Wilhem Meister. In: DUMONT, Louis. L'idéologie allemande. France-Allemagne et retour, op. cit., p. 185-245.

20 "It is really repulsive to see, too, how Goethe regards every moment of his life as important, and, fearing death, prepares his biographical monument. 
Em vez de Goethe, com suas figuras que parecem fragmentos acabados do autor e funcionam como organismos metafísicos, com seu ponto de vista sempre ao alcance da mão e colocando-se a si mesmo como modelo, ${ }^{21}$ Einstein, como autor, se dissolve na experiência. Não é ele que projeta suas visóes do mundo nos objetos sobre os quais teoriza; pelo contrário, são as obras de arte as que contêm a verdade — se é que podemos falar de verdade —, são elas que mobilizam o pensamento. $\mathrm{O}$ que nos leva a concluir que os textos de Einstein não devem ser avaliados como a descrição de uma experiência e sim como um esforço por dar conta de uma realidade apreendida na experiência. À ideologia da Bildung enquanto preservação de uma imortalidade individual que levou à própria superestimaçáo, à valorização do acessório e ao desprezo pelo "outro", Einstein responde eliminando as barreiras entre objeto e sujeito. Sua escrita era indissociável de um posicionamento frente ao clima político e à ideologia dominante; resultava da combinação de uma liberdade criativa, do processamento da situação objetiva e da conjuntura histórico-social.

Porém, os escritos de Carl Einstein requerem um olhar amplo: para ele, como para tantos outros intelectuais daquela época, uma das tarefas impostergáveis da classe em ascensão - o proletariado - era deixar de lado as concepçóes burguesas de cultura, de moral, de ética e de estética. Entender seu pensamento exige colocar lado a lado vanguarda artística e vanguarda política e pensar a respeito do que ele chama da "responsabilidade política dos intelectuais". ${ }^{22}$ Por trás dessa palavra de ordem estaria a questão dos privilégios dos professores universitários que, entre 1890 e 1933, enxergavam o conflito social como a marca da sociedade industrial. ${ }^{23}$ Embora essa tensão tenha tido aspectos destrutivos e levado à transformação da Bildung em quase um título nobiliárquico, também produziu resultados criativos.

So much praise has been given the serenely olympian eye of this virtuoso of the indirect and the metaphor, from which the humanist deduces his vanity and megalomania. [...]

To this man, possessed of an egocentric mania (in other words, to this unecstatic man) the 'I', that personality which he tried to conserve in autobiographies, is a very important matter. Possessed with himself, he overlooks the fact that the 'I' becomes submerged in the act, and is forgotten, and that we can only act insofar as the 'I' is destroyed. For the 'I' is nothing more than a supplementary retrospective perspective; every act is ecstatic and can only come about through the destruction of the 'I'." EINSTEIN, Carl. Obituary 1832-1932. transition, Haia, The Servire Press, v. 21, p. 209, 213, mar. 1932. O original em alemão se perdeu; a tradução para o inglês é de E. Jolas.

${ }^{21}$ SIMMEL, Georg. Individualismo. In: SIMMEL, Georg. Goethe (1913). Buenos Aires: Prometeo Libros, 2005, p. 129-152.

${ }^{22}$ EINSTEIN apud MEFFRE. In: MEFFRE, Liliane. Carl Einstein (1885-1940). Itinéraires d'une pensée moderne. Paris: Presses de l'UniversitéParis-Sorbonne, 2002, p. 84. Frase proferida por Einstein em discurso do 14 de maio de 1919, na Filarmônica de Berlim, a favor da criação de uma Federação dos Conselhos de Soldados.

${ }^{23}$ RINGER, Fritz. Introduction: the Mandarin type. In: RINGER, Fritz. The decline of the German Mandarins: the German Academic Community 1890-1933 (1969). Londres: Wesleyan University Press, 1990, p. 1-13. Para Ringer, os "mandarins alemães" constituem uma elite social e cultural que deve seu status às qualificações intelectuais e não à herança ou à riqueza. Eles argumentavam que a legitimidade do estado não deriva do direito divino nem dos interesses da sociedade e sim dos serviços intelectuais e espirituais da nação, ou seja, dos desejos de uma elite intelectual. 
O engajamento de Einstein com uma escrita que desse conta da experiência vivenciada, no plano teórico, ecoa a Ernst Mach, outro dos pensadores com os quais ele dialoga e considera uma de suas referências. ${ }^{24}$ Filósofo e cientista, escrevendo em um alemão desprovido de jargão técnico, Mach se posiciona contra uma filosofia que tenta responder a questóes profundas mediante a razáo especulativa. Ele sugere desenvolver criticamente a experiência, visando a ultrapassar a barreira entre o psíquico e o físico. Crítico da relação causal entre eventos, defensor da conexão indissolúvel entre sujeito e objeto, Mach conclui que os conceitos, assim como as representaçóes, surgem das sensações e da combinação delas. A matéria-prima da construção dos conceitos, que pertencem tanto ao senso comum quanto à ciência, seriam os dados da experiência sensorial imediata; dado que a experiência precede a distinção entre o físico e o psíquico, a abordagem crítica da experiência seria o modo de evitar tanto os idealismos como os materialismos.

Em vez de uma relação de causalidade, Mach propóe uma dependência funcional — no sentido matemático — dos dados da experiência, que denomina "complexos de elementos" ou sensaçóes. Agrupados segundo três tipos de elementos — objetos externos, meu corpo e o ego —, nenhum deles é estável. Tal instabilidade admite que "consciência" e "matéria" não sejam duas realidades diferentes, inalteráveis, e sim duas modalidades de organizar os dados da experiência. Como resultado dessa instabilidade, aquilo que mais tememos, a aniquilação da permanência pela morte, de fato acontece inúmeras vezes durante a vida. Esses mesmos elementos dos "complexos de sensaçóes" também constituem o "eu"; seus diferentes graus de permanência fazem do "eu" uma unidade indefinida, flexível, imprecisa. Sua intuição do "eu” como função, não como substância metafísica, diz também respeito a uma ênfase nas sensaçóes, uma vez que

O Eu não pode, em nenhum caso, ser salvo. De algum modo esta intuição, e o medo que ela suscita, conduz aos absurdos mais extravagantes, pessimistas ou otimistas, religiosos, ascéticos e filosóficos [...] Renunciamos de bom grado, neste caso, à imortalidade individual. ${ }^{25}$

Em Mach, a continuidade é o meio pelo qual se assegura o conteúdo do eu, que é preservado nos outros depois da morte dos indivíduos: conteúdos de consciência de alcance uni-

\footnotetext{
${ }^{24}$ Einstein se refere à importância do pensamento de Mach na carta datada de junho 1923 a seu amigo Daniel-Henry Kahnweiler (EINSTEIN, Carl; KAHNWEILER, Daniel-Henry. Correspondance 1921-1939. Marselha: André Dimanche Editeur, 1993, p. 54).

25 "The ego must be given up. It is partly the perception of this fact, partly the fear of it, that has given rise to the many extravagances of pessimism and optimism, and to many religious, ascetic and philosophical absurdities. [...] We shall then be willing to renounce to individual immortality." MACH, Ernst. The Analysis of Sensations (1914). Londres: Routledge/Thoemmes Press,1996, p. 24-25. Tradução nossa.

Optamos por traduzir "ego" por "Eu" baseados na frase de Mach, no original em alemão, "Das Ich ist unrettbar" (MACH, Ernst. Die Analyse der Empfindungen und das Verhältnis des Physischen zum Psychischen. 9 Auflage. Iena: Gustav Fischer Verlag, 1919, p. 20).
} 
versal transgridem os limites do indivíduo e cobram existência impessoal e supraindividual, ainda que permaneçam ligados aos indivíduos. A contribuição dos artistas e sábios seria a continuidade entendida como função, preservada nos outros. Sem dúvida, uma compreensão de continuidade que diz respeito à ambiguidade da noçâo de individualismo no pensamento alemão e que atravessa a crítica de Einstein a Goethe.

Há outras características da obra de Einstein que gostaria de ressaltar. Por exemplo, o diálogo que o autor estabelece com o leitor para além dos limites do texto. A meu ver, esse diálogo se organiza não só pelo tema tratado no texto e sim pelo exercício de pensar que esses textos demandam. Em Einstein o pensar não é uma atividade suprema, privilegiada; em Einstein o pensar é, sim, uma engrenagem entre fenômenos, uma vez que seus textos nos colocam frente à obrigaçáo de pensar sobre o modo em que pensamos. Exemplo disso seriam seus artigos sobre cubismo e escultura negra. Neles, Einstein defende um outro modo de representar o espaço, uma alternativa à perspectiva renascentista, baseada no observador ciclope e imóvel. Como leitores, somos levados a tomar consciência de nosso modo de pensar cartesiano, linear, segundo um ponto de fuga que vai do simples ao complexo e no qual as questôes estão mortas, imobilizadas, fixadas; seus artigos, pela sua originalidade na abordagem e na escrita, mostram quantas vezes aceitamos teses de outros sem examiná-las exaustivamente. Frequentemente sua escrita nos confronta com a tendência a fazer uma explicação genealógica dos objetos em vez de desenvolver um raciocínio teórico, como quando ele relaciona fatos plásticos para além dos fatos históricos; outras vezes, nos força a pensar sobre o modo em que atribuímos importância a uma obra dentro de um contexto cultural ao perceber, como leitores, seu esforço por não reconhecer valores determinados a priori; ou ainda, seu empenho em superar as dicotomias clássicas estruturadoras do pensamento decorrentes da divulgação do platonismo na virada do século XIX. A experiência fenomênica dos textos se torna assim tão intensa quanto a das obras de arte, desvendando um Carl Einstein que náo precisava negar a tradição nem aderir a qualquer ortodoxia, com uma liberdade invejável em qualquer artista ou intelectual.

Outra qualidade é o papel que Einstein escolhe enquanto escritor: náo é o do erudito e sim o de um especialista que se entrega à mobilizaçáo da visão, à experiência do espaço, à transformação dos conceitos e da vida. Sua insistência em chamar pintores como Masson e Miró de românticos, em alusão ao romantismo alemão, e não de surrealistas, oferece um claro exemplo disso. Mas deter-nos na leitura de seus trabalhos sobre arte também admite que, como leitores, duvidemos. Essas questôes pertencem de fato aos artistas ou à leitura que Einstein faz dessas "escritas"? Tal ambiguidade nos aproxima a um modo particular de ver a arte como deflagradora de experiências e não como receptáculo de convençôes. Em vez de ver cumpridas nossas expectativas em relação ao contexto ou condiçóes de produção das obras, Einstein nos coloca frente ao sentido dessas obras e nos desafia com uma realidade inegável: por um lado, o fato de que a obra existe está presente e exerce um efeito direto no 
observador. Por outro, essa experiência, ao permanecer intata, deflagra uma etapa posterior de reflexáo na qual tanto as intençóes do artista como os fatos de sua vida se tornam irrelevantes e, portanto, são retirados da obra. Percorrendo o caminho inverso, podemos concluir que, em Einstein, as barreiras entre sujeito e objeto se dissolvem. Por construir uma relação tensa entre o par, inaceitável, sensível/inteligível sem retirar o desconforto intelectual que essa tensão provoca, e simultaneamente envolver e colocar o leitor num papel central, a experiência da leitura de seus textos se assemelha ao labirinto enquanto estrutura espacial completamente ambígua, a um espaço constituído exclusivamente por aberturas.

À busca de novos modos de representar o espaço do cubismo e de uma nova linguagem plástica, Einstein responde com uma busca por uma linguagem escrita - e um uso da linguagem - que permita outro modo de relacionar-se com o mundo. Questóes que ganham outra dimensão à luz do que ele diz a seu amigo Daniel-Henry Kahnweiler, na carta datada de junho de 1923. Depois de expor suas ideias sobre a incapacidade da linguagem para dar conta de algumas experiências vivenciadas, da diferença entre o acontecimento literário e o acontecimento da realidade (que ele qualifica como sendo da ordem do verossímil ou do possível), da realidade da literatura como sucessão das palavras, da insuficiência de ornamentar poeticamente essa sucessão naturalista de palavras ou de recobri-la de metáforas, ele diz: "Não acredito que o cubismo seja apenas uma especialidade óptica; se assim fosse, seria falso, não fundamentado." ${ }^{26}$ Einstein aspira a uma abertura para o futuro como alternativa a um passado reconstruído como continuidade, busca ampliar os limites do mundo pela linguagem como opção ao confinamento criado pelos limites do mundo, estabelecidos pelo próprio limite da linguagem. Ou, nas palavras de seu amigo Georges Braque: "Escrever não é descrever, pintar não é evocar, a verossimilhança não é mais que ilusão de ótica." ${ }^{27}$

Também é possível descobrir seu pensamento na arte que lhe interessava: Einstein defendeu a superioridade plástica do homem frente às convençôes e acompanhou a busca incessante de questôes colocadas pelos pintores cubistas, para eles, mais valiosa do que "fazer" um quadro. Por volta de 1911, Picasso e Braque provaram que materiais diferentes podiam entrar no quadro ao introduzir as colagens e os papiers collés - eles incentivaram a tensão entre planaridade e profundidade e geraram uma multiplicidade de planos que simultaneamente avançam e recuam; Picasso não estilhaçou os objetos simplesmente, ele reagrupou predicados cuidadosamente selecionados. Eles alcançaram a força do quadro por meio de ritmos e contrastes na tela e não pela via da semelhança. Aboliram o espaço euclidiano e o espaço perspectivado como referência. Eliminaram a noção dominante de objeto como

26 "Je ne crois pas que le cubisme soit seulement une spécialité optique; s'il était, il sera faux, car non fondé. Expérience valable, il englobe beaucoup plus et je crois que pour le comprendre, ce n'est qu'une question d'énergie." EINSTEIN, Carl; KAHNWEILER, Daniel-Henry. Correspondance 1921-1939, op. cit., p. 57. Tradução nossa.

${ }^{27}$ BRAQUE, Georges. Aforismos. O dia e a noite (Cadernos 1917-1952). Serrote, São Paulo, n. 5, jul. 2010, p. 142. 
motivo do quadro para dar lugar ao novo conceito de forma, a partir da condensaçáo das experiências do espaço e da totalidade dos movimentos oculares descontínuos; passaram da imitação e do plano imitativo à construção plástica. Foi esse ordenamento livre, realizado com valores plásticos e sustentado pela visão que afastou o cubismo da imitação e abriu a possibilidade da criaçáo autônoma. Cubismo que foi o ponto de partida e a justificativa da análise da forma, da visão e do espaço que Carl Einstein faz em 1915 em Negerplastik.

Defendendo essa apreensão direta do espaço, na pintura cubista e na escultura negra, Einstein vai mais longe e define a história da arte como "a luta de todas as representaçóes ópticas, dos espaços inventados e das figuraçóes". ${ }^{28}$ Uma concepção da história da arte que abre possibilidades para a disciplina, se a enxergamos não mais segundo um modelo positivista, evolucionista e teleológico, e sim como conflito entre fatos plásticos. Quiçá, pela dificuldade enfrentada ao tentar definir o termo e os debates que o enigma do espaço suscitou na época e suscita ainda, a palavra "espaço" seja uma síntese bastante significativa do pensamento de Einstein. Apenas como exemplo: os limites impostos pelas ciências, especificamente a física e a geometria; o pensamento que considera o espaço vinculado à consciência, um índice do desenvolvimento espiritual de um indivíduo ou de uma época; as indagaçôes de Husserl sobre a relaçáo entre espaço e objeto nos primeiros anos do século XX; a intensidade com a qual artistas como Cézanne e os cubistas se dedicaram à tarefa de sua representação - ou, talvez, apresentação. Os problemas que encontramos para circunscrever a noção de espaço — talvez aí esteja toda a sua potência —, tanto quanto o problema filosófico que a noção apresenta, sugerem que mais do que um conceito de espaço, em Einstein a questão é a experiência do espaço.

Aproximando as invençóes cubistas à escultura negra, analisando a arte africana a partir de categorias não africanas, Einstein aspira a uma reestrutura da visão sem referência a um repertório prévio de imagens, próprias de uma obra ou gênero de arte, de um artista ou de um período artístico. Destaca o aspecto plástico dos objetos, resultado de uma experiência não mediada por convençôes e preconceitos. Trata-se do processo visual enquanto experiência original e constitutiva do real: a imagem resultante desse processo não é um resíduo inerte da sensação ou da percepção. Ele se depara com o espaço como instância inseparável da representação do volume na obra de arte. Seu modo de observar a escultura negra e o cubismo diz respeito a um objeto que, em vez de ocupar um espaço, se apropria dele; as bordas e os limites do objeto, suas penetraçóes e vazios, seja na pintura ou na escultura, criam espaço.

Mas a definição de História da Arte de Einstein revela um posicionamento crítico formulado pouco depois de que, em 1924, o governo recém-eleito (conservador e de direita) da Turíngia declare a Bauhaus inviável, reduza os subsídios e pressione para que a escola seja

\footnotetext{
28 "L'histoire de l'art est la lutte de toutes les expériences optiques, des espaces inventés et des figurations". EINSTEIN, Carl. Aphorismes méthodiques (1929). In: EINSTEIN, Carl. Ethnologie de l'art moderne. Marseille: André Dimanche, 1993, p. 17. Tradução nossa.
} 
fechada, com o translado da escola para Dessau em 1925. Ainda, a indulgência diante da emergência de Adolf Hitler e a publicação de Mein $\operatorname{Kampf}(1924)$, em Weimar, e que, junto com o "retorno à ordem", a consigna de servir à pátria, de cuidar a família e dos negócios e a incapacidade de julgar esteticamente uma obra, esboçam o clima político e a hipocrisia da época. Tensão política que também se evidenciou no processo de blasfêmia contra Einstein, em 1922, pela publicação, em Berlim, de sua peça de teatro Die schlimme Botschaft (O mau Evangelho, 1921), uma crítica à situação sociocultural daquela época que inclui os atores da sociedade de Weimar: escritores, jornalistas, filósofos, críticos, artistas, colecionadores, comerciantes, burgueses, industriais, o povo, verdugos, mercenários e espióes desfilam frente ao Cristo crucificado em uma Alemanha de pós-guerra. Fatos que tornam a definição de História da Arte de Einstein ainda mais contundente no momento em que a frase "a história de toda sociedade existente até agora é a história da luta de classes" ${ }^{29}$ do Manifesto Comunista foi transformada em "luta de raças" pelo nazismo.

Pensar essas questôes sob a luz de suas preocupaçôes em relação à escrita e à linguagem que ele expressa a Kahnweiler na carta já citada permite concluir que o valor de seus textos náo decorre apenas de qualidades estéticas que ele enxerga nas obras e sim da potência da figura enraizada no psiquismo e sua capacidade e eficácia de mobilizar o pensamento. $\mathrm{Na}$ arte que interessa a Einstein, seja nas modificaçôes da espacialidade, seja nas forças psíquicas transformadas e reagrupadas em grafismos, o que está em jogo é o fim da concepção positivista do real. Na sua escrita, na verdade uma transcrição da experiência, o que está em jogo é o fim da descrição de estados psicológicos e um entendimento da linguagem não mais como substantivo e sim como verbo.

Einstein não atribui valor estético a um objeto ou a um personagem simplesmente por ter pertencido a um momento histórico e sim pelo modo em que o presente cria sua sombra histórica. Ele busca trazer nossa atenção do geral para o objeto, e por meio dele, indagar a respeito da formação dos elementos constitutivos da forma artística e compreender as vicissitudes culturais, materiais e espirituais de sua época. Sua escrita atuante, pouco compreendida por seus contemporâneos, em um espírito de revolta permanente contra estruturas esclerosadas e fixadas no passado, se sintetiza em frases tais como "o valor da visão reside sobretudo na revolta metamorfótica contra o que é dado". ${ }^{30}$

\footnotetext{
29 "The history of all hitherto existing society is the history of class struggles." MARX, Karl; ENGELS, Friedrich. Manifesto of the Communist Party (1848). In: HUTCHINS, Robert M. (Ed.). Great Books of the Western World n. 50. Marx. Chicago, Londres: William Benton, 1952, p. 419. Tradução nossa. Na nota 2, Marx explicita que se refere à história escrita, uma vez que a organização social existente anterior à história escrita era desconhecida.

30 "Il est absurde de vouloir prouvé des faits à caractère hallucinatoire en faisant appel au naturalisme; car la valeur de la vision réside avant tout dans la révolte métamorphotique contre ce qui est donné.” EINSTEIN, Carl. Georges Braque (1934). Bruxelas: Éditions La Part de l'Oeil, 2003, p. 150. Tradução nossa.

Defensor de uma visão ativa, Einstein entende a percepçáo como uma tendência à adequaçáo. Identificar visão com percepção levou ao desconhecimento de sua força metamorfótica e produtiva. O termo metamorfóti-
} 
O corpo a corpo com sua obra é, sem dúvida, uma experiência transformadora, uma vez que rejeita fórmulas fechadas e imutáveis assim como qualquer tentativa simplista de historicizar sua teoria. O seu campo de atuação fora da Academia, o embate constante com a linguagem e um temperamento incompatível com posiçóes rígidas ou ortodoxas o levaram a uma obra de difícil classificação. Seus textos nos permitem encontrar um homem em pleno exercício do ato de pensar livremente. Mas o compromisso de Einstein com a arte, a história da arte - e sua escrita - e a linguagem é inseparável de seu engajamento político. Seu particular modo de pensar que se evidencia no seu interesse tanto nas formas mais transformadoras da arte moderna, o cubismo, como nas formas arcaicas ainda presentes na atualidade, a arte negra; sua partida para a Espanha em agosto de 1936; seu alistamento junto a Buenaventura Durruti; a carta a Picasso dizendo que "em Espanha eu defendia meu trabalho, a possibilidade de pensar e sentir livremente como indivíduo"; 31 questóes que exigem pensar a complexidade e diferenças entre "liberdade" no sentido político e "liberdade" na especulação filosófica, tanto quanto a tendência das sociedades ocidentais a enxergar a liberdade a partir da dicotomia escravidão/autoritarismo, e não da ausência de liberdade. A linguagem se torna uma ferramenta política. Porque a linguagem "não é só verbo e escrita, é também um método, uma táctica de pensamento, um projeto de compreensão" ${ }^{32}$

\section{Referências bibliográficas}

BOIS, Yve-Alain. Ideologia da forma. Novos estudos CEBRAP [online], n. 76, 2006, p. 237-249. Disponível em: <http://www.scielo.br/scielo.php?script=sci_arttext\&pid $=$ S0101-33002006000300013>. Acesso em: 5 out. 2015 .

BRAQUE, Georges. Aforismos. O dia e a noite (Cadernos 1917-1952). Tradução de Samuel Titan Jr. Serrote, São Paulo, n. 5, p. 139-153, jul. 2010.

BRITO, Ronaldo. Fato estético e imaginação histórica. In: DE PAIVA, Márcia; MOREIRA, Maria Ester (Orgs.). Cultura. Substantivo Plural. São Paulo: Editora 34, 1996, p. 193-206.

DIDI-HUBERMAN, Georges. O anacronismo fabrica a história: sobre a inatualidade de Carl Einstein (2000). In: ZIELINSKY, Mônica (Org.). Fronteiras. Arte, crítica e outros

co não existe em português — também não em alemão. Segundo a nota de Liliane Meffre, é um neologismo criado e utilizado frequentemente por Einstein para expressar o poder de transformação, de metamorfose própria à arte (EINSTEIN, Carl. Georges Braque [1934]. op. cit., p. 32, nota 4).

${ }^{31}$ Carta datilografada de Carl Einstein a Picasso, anexada à carta a Kahnweiler, enviada em 6 de janeiro de 1939. "Je savais toujours que je défendai en Espagne mon travail, la possibilité de penser et de sentir librement comme individu." EINSTEIN, Carl; KAHNWEILER, Daniel-Henry. Correspondance 1921-1939, op. cit., p. 114. Tradução nossa.

${ }^{32}$ BRITO, Ronaldo. Fato Estético e Imaginação Histórica. In: DE PAIVA, Márcia; MOREIRA, Maria Ester (Orgs.). Cultura. Substantivo Plural. São Paulo: Editora 34, 1996, p. 197. 
ensaios. Porto Alegre: Ed. UFRGS, 2003.

. Tableau $=$ coupure. Expérience visuelle, forme et symptôme selon Carl Einstein. Cahiers do Musée national d'art moderne, n. 58. Paris: Centre Georges Pompidou, 1996, p. $5-27$.

DUMONT, Louis. Lidéologie allemande. France-Allemagne et retour. Paris: Gallimard, 1991.

EINSTEIN, Carl. Aphorismes méthodiques (1929). In: EINSTEIN, Carl. Ethnologie de l'art moderne. Marseille: André Dimanche, 1993, p. 17-20.

. Herr Giorgio Bebuquin. In: Die Opale 2. Blätter für Kunst \& Literature. Leipzig: J. Zeitler, 1907, p. 169-175.

Bebuquin oder die Dilettanten des Wunders. Berlim-Wilmersdorf: Verlag Die Aktion, 1912. Prefácio de Franz Blei.

Bebuquin. Berlim-Wilmersdorf: Verlag der Wochenschrift Die Aktion, 1917. (Aktionsbücher der Aeternisten, Band 5).

Bebuquin oder die Dilettanten des Wunders. In: EINSTEIN, Carl. Werke. Band 1. 1908-1918. Editado por Rolf-Peter Baacke e Jens Kwasny. Berlim: Medusa Verlag, 1980, p. 73-114.

. Bebuquin ou les Dilettantes du Miracle (1912). Tradução de Sabine Wolff. Paris: EST-Samuel Taste Éditeur, 1987.

. Georges Braque. (Ed. des Chroniques du Jour, 1934). Tradução de Jean-Loup Korzilius. Publicação dirigida, revista, apresentada e anotada por Liliane Meffre. Bruxelas: Éditions La Part de l'Oeil, 2003.

. Kleine Autobiographie. In: Werke, Band 3. 1929-1940. Editado por Marion Schmid e Liliane Meffre. Berlim/Viena: Medusa Verlag, 1985, p. 109-111.

. L'art nègre. Remarques sur la méthode (cap. 1). Action. Cahiers de philosophie et d'art,Paris, v. 2, n. 9, p. 12-16, out. 1921.

. Negerplastik. Lepizig: Verlag der Weißen Bücher, 1915.

. Negerplastik. Reedição. Munique: Kurt Wolff Verlag, 1920.

. Negerplastik (1915). Tradução de Inês de Araujo. Concinnitas, Rio de Janeiro, UERJ, v. 1, n. 12, p. 165-177, jul. 2008.

. Negerplastik (1915). Florianópolis: Editora UFSC, 2011. Publicado sob a direção de L. Meffre. Legendas estabelecidas por E. Bassani e J.-L. Paudrat. Traduçấo de I. de Araujo. Apresentação de L. Meffre. Anexo de R. Conduru.

. Obituary: 1832-1932. transition, Haia, The Servire Press, v. 21, p. 207-214, mar. 1932. 
EINSTEIN, Carl; KAHNWEILER, Daniel-Henry. Correspondance 1921-1939. Tradução, apresentação e notas de Liliane Meffre. Marselha: André Dimanche Editeur, 1993.

GOMBRICH, Ernst. Hegel e a história da arte. Tradução de Teresa da Costa. Gávea. Revista de história da arte e arquitetura. Rio de Janeiro, PUC-Rio, n. 5, p. 57-72, abr. 1988.

. In Search of Cultural History. Londres: Oxford University Press, 1969.

KAHNWEILER, Daniel-Henry. Juan Gris. Sa vie, son oeuvre, ses écrits. Paris: Gallimard, 1946.

MACH, Ernst. Die Analyse der Empfindungen und das Verhältnis des Physischen zum Psychischen. 9 Auflage. Iena: Gustav Fischer Verlag, 1922. Disponível em: <https://archive. org/details/dieanalysederemp00mach>. Acesso em: 17 abril 2015.

.The Analysis of sensations (1914). Tradução de C. M. Williams. Londres: Routledge/Thoemmes Press, 1996.

MARX, Karl; ENGELS, Friedrich. Manifesto of the Communist Party (1848). In: HUTCHINS, Robert M. (Ed.). Great Books of the Western World n. 50. Marx. Tradução de Samuel Moore (1888). Chicago, Londres: William Benton, 1952, p. 415-434.

MEFFRE, Liliane. Carl Einstein 1885-1940. Itinéraires d'une pensée moderne. Paris: Presses de l'Université Paris-Sorbonne, 2002.

- Carl Einstein et la problématique des avant-gardes dans les arts plastiques.Berna:

Éditions Peter Lang, 1989.

NAVES, Rodrigo. Entrevista com Rodrigo Naves (realizada em dezembro 2005).Número, n. 7. Disponível em: <http://www.forumpermanente.org/rede/numero/rev-numero7/ entrevRodrigoNav>. Acesso em: 5 out. 2015.

RINGER, Fritz. Introduction: the Mandarin type. In: The decline of the German Mandarins: the German Academic Community 1890-1933 (1969). Londres: Wesleyan University Press, 1990, p. 1-13.

SIMMEL, Georg. L'individualisme; L'individu et la liberté. Philosophie de la modernite: la femme, la ville, l'individualisme.Introdução e tradução de Jean-Louis Vieillard-Baron.Paris: Payot, 1989. Tomo 1, p. 281-304.

. Individualismo. In: SIMMEL, Georg. Goethe (1913). Tradução de José Rovira Armengol (1949). Buenos Aires: Prometeo Libros, 2005, p. 129-152. Introdução de D. Mundo. 